Article

\title{
Cellulose Nanofibre Mesh for Use in Dental Materials
}

\section{Stephen A. Boyd, Bo Su, Jonathan R. Sandy and Anthony J. Ireland *}

School of Oral and Dental Science, University of Bristol, Lower Maudlin Street, Bristol BS1 2LY, UK; E-Mails: stephenboyd1980@googlemail.com (S.A.B.); B.Su@bristol.ac.uk (B.S.); Jonathan.Sandy@bristol.ac.uk (J.R.S)

* Author to whom correspondence should be addressed; E-Mail: tony.ireland@bristol.ac.uk; Tel.: +44-117-342-4355; Fax: +44-117-342-2601.

Received: 17 April 2012; in revised form: 2 July 2012 / Accepted: 2 July 2012 /

Published: 11 July 2012

\begin{abstract}
The aim of this study was to produce a 3D mesh of defect free electrospun cellulose acetate nanofibres and to use this to produce a prototype composite resin containing nanofibre fillers. This might find use as an aesthetic orthodontic bracket material or composite veneer for restorative dentistry. In this laboratory based study cellulose acetate was dissolved in an acetone and dimethylacetamide solvent solution and electrospun. The spinning parameters were optimised and lithium chloride added to the solution to produce a self supporting nanofibre mesh. This mesh was then silane coated and infiltrated with either epoxy resin or an unfilled Bis-GMA resin. The flexural strength of the produced samples was measured and compared to that of unfilled resin samples. Using this method cellulose acetate nanofibres were successfully electrospun in the $286 \mathrm{~nm}$ range. However, resin infiltration of this mesh resulted in samples with a flexural strength less than that of the unfilled control samples. Air inclusion during preparation and incomplete wetting of the nanofibre mesh was thought to cause this reduction in flexural strength. Further work is required to reduce the air inclusions before the true effect of resin reinforcement with a 3D mesh of cellulose acetate nanofibres can be determined.
\end{abstract}

Keywords: nanofibre; electrospinning; fillers; dental; composites 


\section{Introduction}

In recent years there has been an ever increasing demand for more aesthetic orthodontic appliances. Labial fixed appliances are still the most popular fixed appliance and the aesthetic brackets currently available are of two main types, ceramic and polymeric. While both demonstrate good aesthetics at placement, they each suffer from drawbacks during clinical use [1].

Ceramic brackets are made from either mono or polycrystalline alumina, which is relatively inert and retains an aesthetic appearance throughout a two year course of fixed appliance therapy. However, this material has a low fracture toughness and a high surface hardness. As a result it is not uncommon for ceramic orthodontic brackets to fracture in thin section, principally at the tie wings during service. Conversely if they are opposed by natural teeth, the high surface hardness of the ceramic may result in unwanted wear of the opposing tooth. Finally, the relatively high compressive strength, but low tensile strength, can make removal at debond both difficult and sometimes unpredictable and may even result in undesirable enamel fracture.

Polymeric brackets were originally made from unfilled polycarbonate [2] and have since been made from materials such as polyoxymethylene and polyurethane. These materials have a low abrasion resistance, may absorb water in the oral environment, demonstrate a relatively low stiffness and like other viscoelastic materials, creep over time. This translates to a tendency to wear within a relatively few months in service and a reduced ability to effectively transfer torqueing forces to the teeth.

Polymers used as restorative materials have undergone many developments since their introduction, particularly with respect to filler material, particle size and content [3]. Various copolymers have also been added to alter the handling and mechanical properties of both the unpolymerised and final polymerised material. Although filler particles and metal slot inserts have been added to polymeric orthodontic brackets in an attempt to improve the mechanical properties, much less work has been done on altering the filler content of such materials than in the field of restorative dentistry.

We have previously reported that it is possible to produce silica nanofibres using an electrospinning technique, which can then provide fibre reinforcement of composite materials [4]. In the process of electrospinning, a carrier polymer solution containing silica colloids is ejected through a fine bore needle when an electrical potential is applied between the needle tip and a collecting plate at some distance from the tip. As the polymer is drawn across the electrical potential, very fine nanofibres of silica/polymer are produced as the solvent in carrier solution evaporates during the process. Pure silica nanofibres can be obtained upon the pyrolysis of polymer at high temperature.

An advantage of producing fibres with diameters at the nano scale is that at a diameter of less than the wavelength of visible light, the fibre composite would become translucent or transparent because of less reflectance in the multi-phase composite. Although the presence of 'invisible' reinforcing fibres within a dental composite material would be desirable, there is concern that such fibres may be something of a health hazard if they should escape from the material during service. Particles with an aerodynamic diameter of less than $5 \mu \mathrm{m}$ can reach the alveoli of the lungs [5] and non-resorbable low aerodynamic diameter fibres such as those of asbestos, are known to be particularly hazardous. However, not all electrospun fibres need to be made from non-resorbable materials. It is also possible to electrospin fibres from resorbable materials such as cellulose acetate [6]. These may be less hazardous due to their resorbable nature and indeed they have already found uses within wound dressings [7]. 
The aims of the current study were therefore to try to produce a novel 3D nanofibre cellulose acetate mesh using the technique of electrospinning, to then embed such a 3D mesh within a polymer and finally to determine the effect the 3D filler has on the mechanical properties of the polymer.

\section{Results and Discussion}

\subsection{Production of Defect Free Cellulose Acetate Nanofibres}

In order to produce defect free fibres, acetone and DMAc were used as polymer solutions, initially at a ratio of 2:1. The polymer concentration and spinning conditions were then altered to optimise the fibre morphology. At cellulose acetate concentrations of $14.5 \%$ and $17 \%$ and using a range of spinning parameters (Table 1), light microscopy revealed extensive beading of the fibres.

Table 1. Solutions and spinning parameters tested to investigate the production of defect free fibres.

\begin{tabular}{|c|c|c|c|c|}
\hline $\begin{array}{l}\text { Solution } \\
\text { Number }\end{array}$ & Solution & $\begin{array}{c}\text { Voltage } \\
(\mathrm{kV})\end{array}$ & $\begin{array}{l}\text { Distance of the needle tip } \\
\text { to collecting plate (cm) }\end{array}$ & $\begin{array}{l}\text { Flow rate } \\
(\mu \mathrm{L} / \mathrm{min})\end{array}$ \\
\hline 1 & $\begin{array}{l}\text { 14.5\% Cellulose acetate } \\
\text { 2:1 Acetone: DMAc }\end{array}$ & $12,15,17,20$ & $10,15,20$ & $5,10,16$ \\
\hline 2 & $\begin{array}{l}\text { 17\% cellulose acetate } \\
\text { 2:1 Acetone: DMAc }\end{array}$ & $10,15,17$ & 15,30 & 16 \\
\hline 3 & $\begin{array}{l}\text { 20\% cellulose acetate } \\
\text { 2:1 acetone: DMAc }\end{array}$ & 15 & 17.5, 30 & $10,15,25$ \\
\hline 4 & $\begin{array}{l}\text { 21.5\% cellulose acetate } \\
\text { 2:1 acetone: DMAc }\end{array}$ & $10,15,20$ & 30 & $0.2,0.5,1,5,10$ \\
\hline 5 & $\begin{array}{l}\text { 20\% cellulose acetate } \\
\text { 3:1 acetone: DMAc }\end{array}$ & 15 & 30 & 5,10 \\
\hline 6 & $\begin{array}{l}\text { 17\% cellulose acetate } \\
\text { 3:1 acetone: DMAc }\end{array}$ & 15 & 30 & 5,10 \\
\hline
\end{tabular}

The presence of excess solvent on the microscope slide following electrospinning suggested that a further increase in polymer concentration might not only reduce the presence of beading, but also aid complete evaporation of the solvent. At a cellulose acetate concentration of $20 \%$ and with the spinning parameters of $15 \mathrm{kV}$ at a distance of $17.5 \mathrm{~cm}$ and a flow rate of $15 \mu \mathrm{L} / \mathrm{min}$, continuous defect free fibres were produced (Figure 1). Splashes of solvent were still visible on the collecting plate, therefore both the operating voltage and collecting distance were increased to encourage increased whipping of the fibres in order to drive off the excess solvent.

The flow rate was also adjusted in order to determine the minimum flow rate that could be used. The optimum conditions were determined to be $15 \mathrm{kV}$ at a spinning distance of $30 \mathrm{~cm}$ with a flow rate of $10 \mu \mathrm{L} / \mathrm{min}$. This produced regular, defect free fibres in the 400 to $700 \mathrm{~nm}$ range (Figure 2) as determined by measuring 20 fibre diameters under SEM. 
Figure 1. SEM image showing regular defect free fibres produced using $20 \%$ cellulose acetate solution with spinning parameters of $15 \mathrm{kV}$ at a distance of $17.5 \mathrm{~cm}$ and a flow rate of $15 \mu \mathrm{L} / \mathrm{min}$.

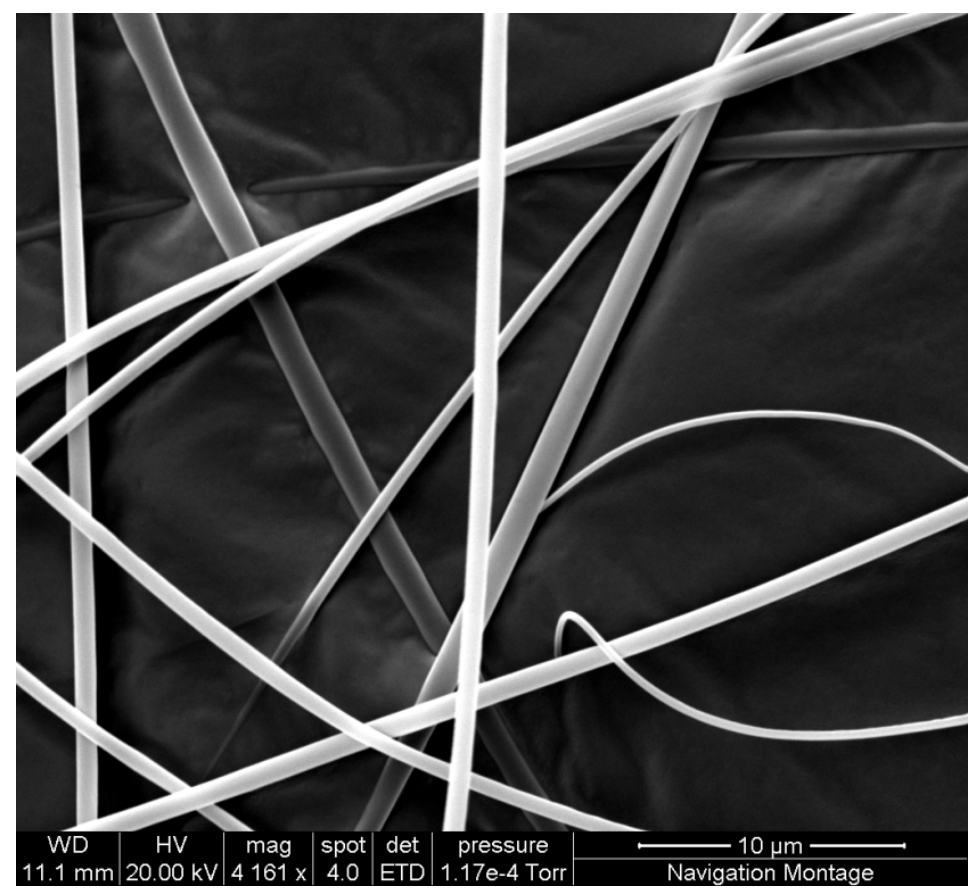

Figure 2. SEM image of regular defect free cellulose acetate nanofibres in the $480 \mathrm{~nm}$ range produced using 21.5\% cellulose acetate solution, with the spinning parameters of $10 \mathrm{kV}, 30 \mathrm{~cm}$ needle tip to collecting plate distance and a $5 \mu \mathrm{L} / \mathrm{min}$ flow rate.

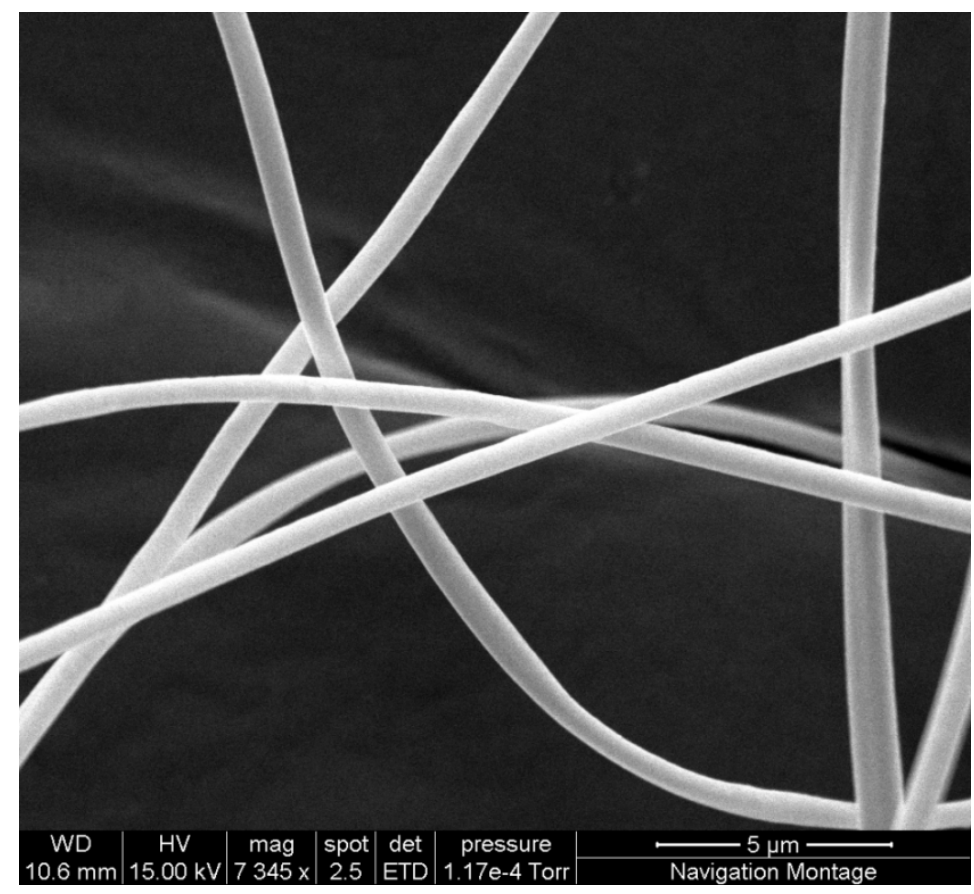


However, a further increase in polymer concentration to $21.5 \%$ again produced defect free fibres. In this case not only were defect free fibres produced, but it showed a trend towards a small reduction in fibre size with reduced operating voltage and flow rates (Table 2).

Table 2. The effect of manipulation of spinning parameters on fibre diameter using Solution 4 (21.5\% cellulose acetate, 2:1 acetone: DMAc).

\begin{tabular}{cccccc}
\hline $\begin{array}{c}\text { Operating } \\
\text { Voltage } \mathbf{( k V )}\end{array}$ & $\begin{array}{c}\text { Distance } \\
(\mathbf{c m})\end{array}$ & $\begin{array}{c}\text { Flow Rate } \\
(\boldsymbol{\mu} \mathbf{L} / \mathbf{m i n})\end{array}$ & $\begin{array}{c}\text { Mean Fibre } \\
\text { Diameter }(\mathbf{n m})\end{array}$ & $\begin{array}{c}\text { Minimum Fibre } \\
\text { Diameter }(\mathbf{n m})\end{array}$ & $\begin{array}{c}\text { Maximum Fibre } \\
\text { Diameter }(\mathbf{n m})\end{array}$ \\
\hline 20 & 30 & 10 & 895 & 485 & 2077 \\
20 & 30 & 5 & 1000 & 465 & 2239 \\
10 & 30 & 10 & 537 & 228 & 884 \\
10 & 30 & 5 & 483 & 205 & 746 \\
\hline
\end{tabular}

Although the viscosity of the electrospinning solution was not measured in this study, it has been previously shown that increasing the polymer concentration results in an increase in the viscosity [8]. Viscosity is a significant factor affecting the ability to produce electrospun fibres and is specific to different polymers, is affected by temperature [6] and is directly related to electrospun fibre diameter. In general as the viscosity increases so does fibre diameter [9] and therefore in order to produce defect free fibres of small diameter, a balance has to be struck between polymer concentration and viscosity.

It has also previously been shown that cellulose acetate fibre size distributions are strongly related to the molecular weight of the cellulose acetate. The lower the molecular weight the larger the fibre size distribution and the greater the number of bead defects [10]. Conversely, increasing the molecular weight leads to the production of fibres of a more consistent diameter and with fewer defects such as beading. Compared to previous studies the cellulose acetate used in this investigation had a relatively low molecular weight. This may explain why increasing the optimal polymer concentration to $21.5 \%$ in order to eliminate beading was higher than the $14.5 \%$ polymer concentration previously suggested by Liu and Hseih (2002) [6]. Using a similar molecular weight cellulose acetate polymer and with the same solvent solution, Liu and Tang (2007) [8] produced defect free electrospun nanofibres of a similar fibre diameter. They also described the presence of significant beading of the fibres at polymer concentrations below $20 \%$.

The optimum flow rate in this experiment varied according to the solution parameters, but the optimum flow rate for the production of a flat membrane of fibres was determined to be $5 \mu \mathrm{L} / \mathrm{min}$. In general the diameter of the spun fibres was noted to reduce with decreasing flow rates.

\subsection{The Effect of Spinning Parameters}

As with the flow rate a small reduction in fibre diameter was noted with reduced operating voltage. A minimum operating voltage is required to overcome the surface tension of the polymer solution and to permit the formation of a Taylor cone. Increasing the operating voltage beyond this point has the effect of accelerating the passage of the electrospun fibres towards the collecting plate and reducing the whipping of the fibres. The whipping phase, once the fibre has been ejected from the Taylor cone, is an important step in the reduction of the fibre diameter as the jet is stretched to many times its 
original length due to bending instability caused by the electrical charge carried in the fibres. A reduction in the whipping process will therefore cause an increase in the produced fibre diameter [11]. The optimum operating voltage for production of a flat nanofibre membrane was determined to be $10 \mathrm{kV}$.

Increasing the distance between the needle tip and the collecting plate from $17.5 \mathrm{~cm}$ to $30 \mathrm{~cm}$ appeared to aid evaporation of the solvent from the fibres. However this increase in distance appeared to have little effect on the diameter of the produced fibres This finding is in agreement with previous work carried out on silk nanofibres, which also found that increasing the spinning distance had no effect on the diameter of the fibres produced [12].

In this present experiment the smallest diameter defect free fibres that were produced had a mean diameter of $483 \mathrm{~nm}$, which is similar to that reported by a previous study [8] and which will still be visible to the naked eye. Smaller $90 \mathrm{~nm}$ diameter, invisible fibres have been produced, but these were beaded and not defect free [13]. There have been no reports of the production of small diameter invisible defect free fibres of cellulose acetate nanofibres in the $100 \mathrm{~nm}$ range.

\subsection{Production of 3D Nanofibres.}

Although nanofibres were produced in this experiment, initially they had only been in the form of a flat membrane and yet the aim of this study was to produce a 3D fibre mesh for resin reinforcement. Previous work on the production of nanofibre reinforced composites has involved resin infiltration of flat non woven mats of nanofibres, resulting in the production of laminate composites. However, three common causes of failure of laminate composites have been identified, namely micro-cracking, fibre breakage and delamination [14]. If a 3D nanofibre reinforcement were instead used it might at least eliminate the most common of these causes of failure, delamination. Once again a number of different methods may be used to produce a 3D mesh of fibres, including substitution of the metal grounded collection plate with liquid nitrogen, or a non-conducting surface, as well as the use of a heated collection plate. All three techniques have limitations. Spinning onto the surface of liquid nitrogen results in freezing of the fibres along with any remaining solvent, which is then difficult to eliminate. Collection onto a non conducting plate means that the electrostatic charge generated during the spinning process remains within the fibres, leading to fibre repulsion and the generation of the $3 \mathrm{D}$ mesh. However, grounding of the fibres in order to manipulate them prior to resin infiltration may then result in collapse of the 3D structure. The use of a heated collection plate can lead to an increase in the ambient temperature in the electrospinning chamber, which in turn will have an adverse effect on the spinning process as excessive solvent evaporation at the needle tip can result in solidification of the Taylor cone. This would then require compensatory cooling of the needle tip and syringe using a water jacket.

A simpler solution is to ensure complete evaporation of the solvent solution before the fibres reach the collection plate, by the use of an ionic salt. The addition of an ionic salt to the polymer solution results in a higher charge density on the surface of the jet during spinning, resulting in a greater electric charge being carried by the electrospinning jet. This results in a greater elongation force, caused by increased whipping and electrostatic repulsion as the fibres pass from the needle tip to the collecting plate. This whipping in turn leads to an increase in the evaporation of solvent. Another benefit of the increased whipping is the production of smaller diameter fibres [15]. However, using $0.5 \%$ lithium chloride in a $21.5 \%$ cellulose acetate solution, a 2:1 solvent solution of acetone: DMAc, along with the 
optimum conditions previously determined (namely $10 \mathrm{kV}$ at a distance of $30 \mathrm{~cm}$ and flow rate of $5 \mu \mathrm{L} / \mathrm{min}$ ), no fibres were produced. A lower $1 \mu \mathrm{L} / \mathrm{min}$ flow rate was insufficient to support any spinning while $2 \mu \mathrm{L} / \mathrm{min}$ and $3 \mu \mathrm{L} / \mathrm{min}$ flow rates produced fibres which appeared to interfere with the spinning process, leading to solidification at the Taylor cone. To counteract this, the polymer concentration was first reduced to $20 \%$ and then subsequently to $17.5 \%$. Initially the $17.5 \%$ cellulose acetate solution appeared to produce 3D fibres, but closer inspection revealed that the solution was solidifying at the needle tip and then being drawn to the collecting plate, creating droplets on long fibres. This was due to excessive solvent evaporation and therefore the solvent ratio was altered to increase the proportion of DMAc, reducing the overall volatility of the polymer solution. A change in the solvent solution ratio to 3:2 acetone: DMAc also failed to prevent excessive solvent evaporation with both $20 \%$ and $17.5 \%$ cellulose acetate solutions. A solution containing $17.5 \%$ cellulose acetate, $1 \%$ lithium chloride, and acetone: DMAc in a 1:1 ratio produced 3D fibres following further manipulation of the spinning parameters. 3D fibres were produced using the following parameters of operating voltage, needle tip to collecting plate distance, and flow rate:

- $30 \mathrm{kV}, 15 \mathrm{~cm}$ and $10 \mu \mathrm{L} / \mathrm{min}$

- $25 \mathrm{kV}, 15 \mathrm{~cm}$ and $10 \mu \mathrm{L} / \mathrm{min}$

- $25 \mathrm{kV}, 15 \mathrm{~cm}$ and $5 \mu \mathrm{L} / \mathrm{min}$

- $30 \mathrm{kV}, 15 \mathrm{~cm}$ and $1 \mu \mathrm{L} / \mathrm{min}$

The final set of parameters permitted the smoothest spinning at the needle tip and an immediate build up of 3D fibres, suggesting that complete evaporation of the solvent solution had occurred as the jet passed from the needle tip to the collecting plate. An image of the collected fibres under the SEM may be seen in Figure 3. The increased charge density of the solution caused a reduction of the mean fibre diameter of the nanofibres from $483 \mathrm{~nm}$ to $286 \mathrm{~nm}$, based on the measurement of 20 fibres.

Figure 3. SEM image of 3D fibre network produced with a solution of $17.5 \%$ cellulose acetate, 1\% lithium chloride and 1:1 DMAc: acetone solvent solution. The spinning parameters were $30 \mathrm{kV}, 15 \mathrm{~cm}$ and $1 \mu \mathrm{L} / \mathrm{min}$. Notice how the fibres are branched. Areas of precipitation of lithium chloride may be seen on some of the fibres.

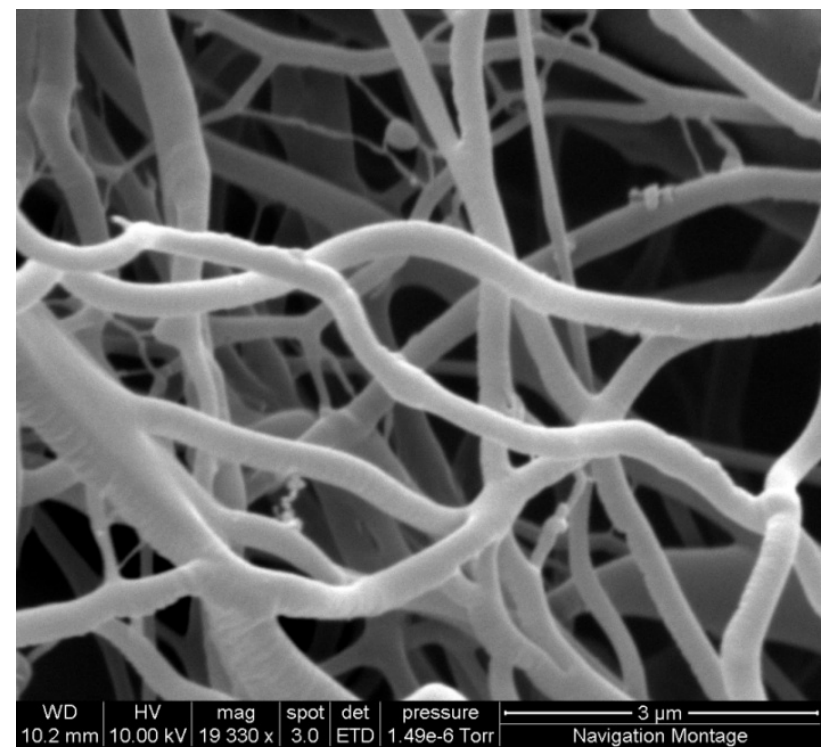


Even with the optimal concentrations, $\mathrm{kV}$ and flow rates, after a period of 30 min the collected fibres started to back up towards the needle tip (Figure 4), which eventually prevented complete evaporation of the solvent due to a decrease in the potential space for whipping of the fibres. To counteract this and to maximise the rate of fibre collection, the distance to the collection plate was increased to $30 \mathrm{~cm}$ and a second syringe and needle was connected in a tandem circuit. The flow rate was also increased to $2 \mu \mathrm{L} / \mathrm{min}$ in order to maintain the spinning process over time.

Figure 4. Image of the collection of 3D fibres using solution 13 and a double needle setup. Notice how the 3D fibres are backing up towards the needle tip.

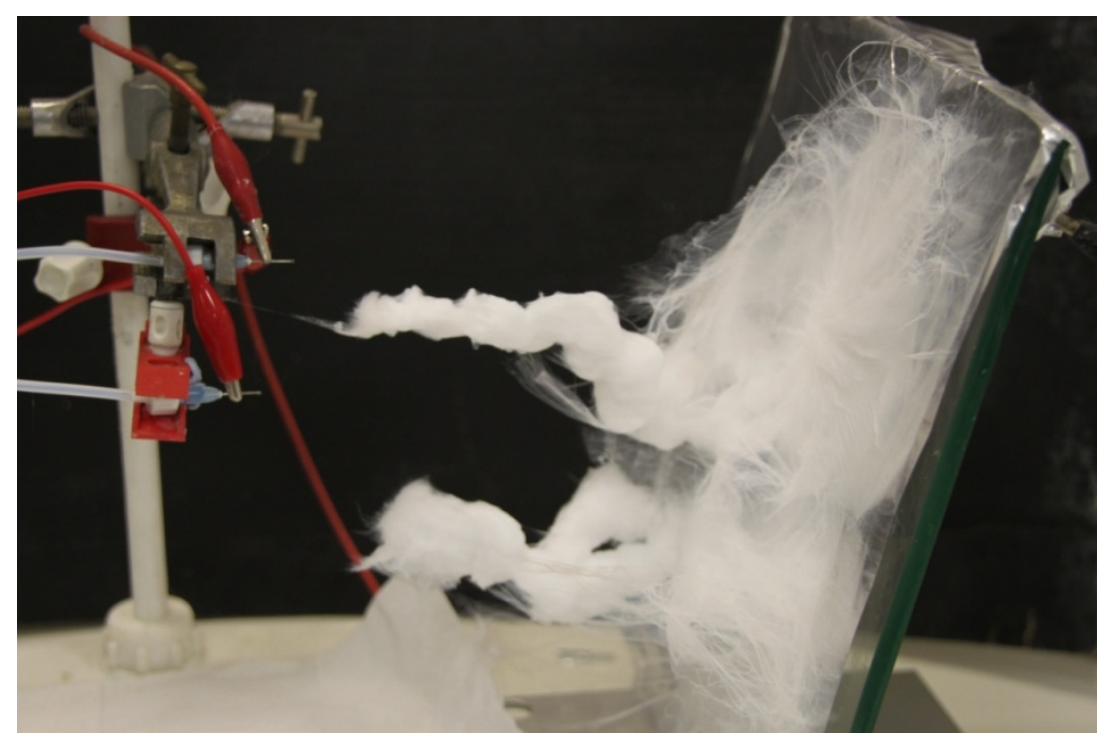

When observed under SEM a precipitation of salt was observed on a number of the nanofibres. Therefore the concentration of lithium chloride was reduced from $1 \%$ to $0.5 \%$. This appeared to reduce the precipitation without having any discernable effect on fibre diameter or morphology.

Of note was the fact that the spinning process appeared to be sensitive to the ambient temperature and humidity. On a number of occasions, using the previously described optimum conditions, electrospinning failed to produce a 3D membrane if the ambient temperature dropped below $20{ }^{\circ} \mathrm{C}$. This produced significant problems in consistent fibre production as the temperature could not be easily controlled.

\subsection{Filler Loading}

The percent filler content by weight of the epoxy and the Bis-GMA samples are illustrated in Table 3. It can be seen that the filler loadings of both the epoxy and Concise samples produced in this experiment were far below typical values for dental composites.

The loadings ranged from $1.35 \%$ to $8.3 \%$ by weight, a typical dental composite may comprise up to $75 \%$ filler loading by weight. Nanometre sized fillers are widely believed to have the potential to substantially improve the mechanical properties of composites at very low filler loadings. This is because their large interfacial area enables the applied load to be transferred to the resin filler interface [16]. Typical filler loading values for nanofibre reinforced composites range from 3 to $15 \%$ [17]. A Bis-GMA resin reinforced with 5\% by weight nylon nanofibres has been shown to improve flexural strength by $36 \%$ [9], therefore the filler loadings used in this investigation were well 
within the range expected to improve the physical properties. However, incomplete wetting and air inclusion resulted in a reduction in the flexural strength. Strong interfacial bonding of the nanofibre fillers to the resin phase of the matrix has been shown to be important in the reinforcement of composites [18].

Table 3. Filler loading by weight for the filled specimens.

\begin{tabular}{cccccc}
\hline \multirow{2}{*}{ Polymer } & \multicolumn{5}{c}{ Filler Loading (\%) by weight } \\
\cline { 2 - 6 } & Obs & Mean & SD & Min & Max \\
\hline Filled epoxy & 5 & 4.08 & 2.56 & 1.51 & 8.30 \\
Filled epoxy and silane & 5 & 2.66 & 1.83 & 1.35 & 5.33 \\
Filled Bis-GMA and silane & 5 & 3.23 & 1.78 & 1.39 & 6.15 \\
\hline
\end{tabular}

Examination of the fractured surfaces of both the epoxy and Concise filled samples (Figure 5) showed limited resin filler interaction, therefore there was little potential for load transfer from the nanofibres to the resin matrix. Infiltration of the epoxy resin was carried out under vacuum in an attempt to reduce the inclusion of air in the final samples. Nevertheless, macroscopically the samples exhibited opaque areas where it was initially unclear whether it was due to air inclusion, or clumping of the nanofibres. The Concise samples could not be prepared under vacuum due to the rapid polymerisation and although less viscous than the epoxy resin, complete filling of the mould and fibre wetting was again not possible. The use of a low viscosity, light cured resin cured in a vacuum oven might produce significantly fewer air inclusions within the final composite, an approach which has been shown to be effective in the production of laminate nanofibre reinforced composites [19].

Figure 5. SEM image of the fractured surface of 3D nanofibres filled epoxy resin clearly showing how some fibres have not been infiltrated by the resin.

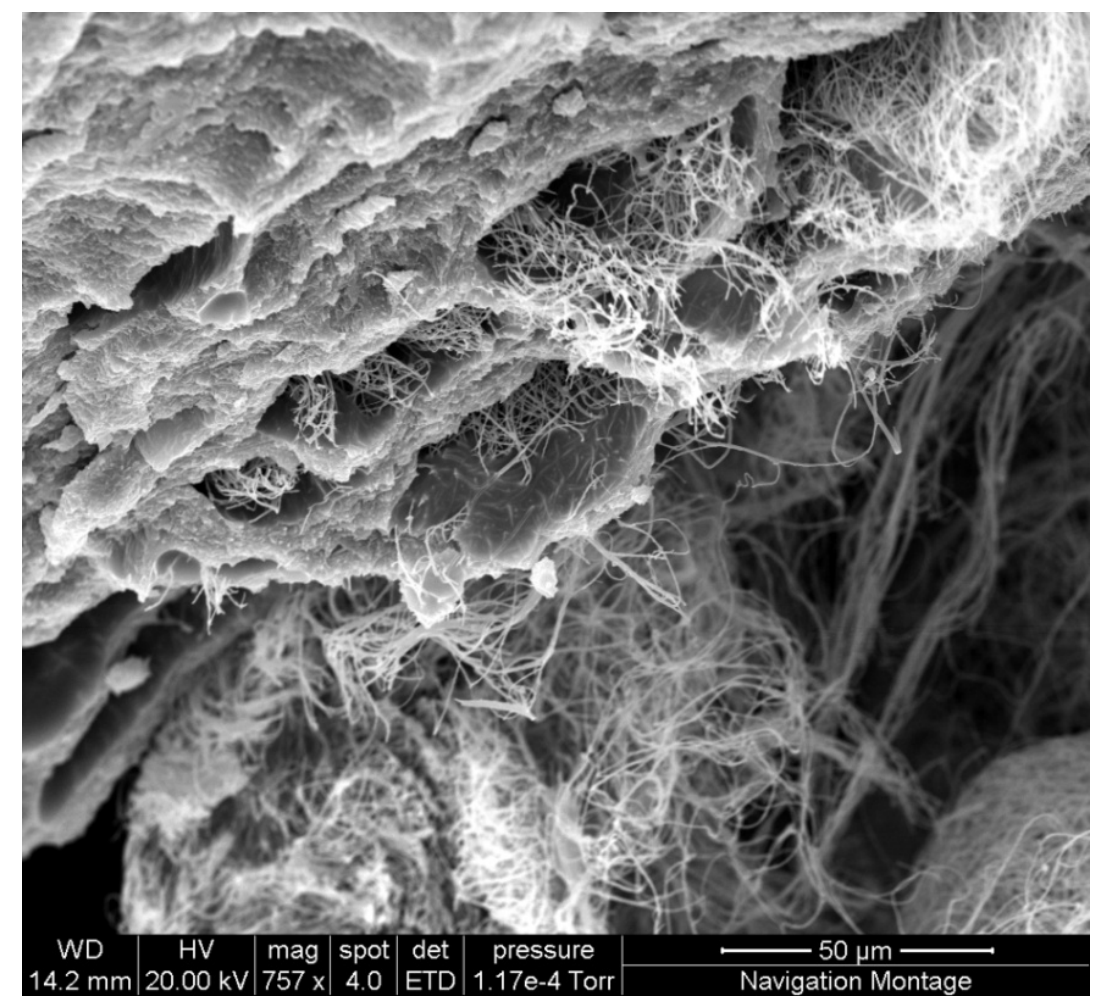




\subsection{Three Point Bend Test}

The results of the 3 point bend testing are illustrated in Table 4 along with the boxplots and means and 95\% confidence interval plots (Figures 6-9). It can be seen that the mean flexural strengths for the unfilled epoxy and unfilled Bis-GMA are 94.40 and 96.95 MPa respectively. The inclusion of the 3D fibre mesh reduced the mean flexural strength to $66.75 \mathrm{MPa}$ for the silane coated fibres in epoxy and 31.54 MPa for Bis-GMA. For the non-silanated fibres in epoxy the mean flexural strength was reduced to $61.53 \mathrm{MPa}$.

Table 4. Data summary of flexural strength (MPa) for the epoxy resin and Bis-GMA unfilled and filled samples.

\begin{tabular}{ccccccc}
\hline & \multicolumn{6}{c}{ Flexural Strength (MPa) } \\
\cline { 2 - 7 } & Obs & Mean & SD & Min & Max & $\begin{array}{c}\text { 95\% Confidence } \\
\text { Intervals of Mean }\end{array}$ \\
\hline Unfilled epoxy & 10 & 94.40 & 14.91 & 71.21 & 120.26 & 83.73 to 105.06 \\
Filled epoxy & 5 & 61.53 & 31.91 & 26.86 & 100.71 & 21.91 to 101.14 \\
Filled epoxy and silane & 5 & 66.75 & 13.65 & 44.21 & 78.09 & 49.81 to 83.70 \\
Unfilled Bis-GMA & 5 & 96.95 & 8.07 & 89.60 & 106.55 & 86.93 to 106.97 \\
Filled Bis-GMA and silane & 5 & 31.54 & 5.60 & 25.89 & 38.33 & 25.59 to 38.50 \\
\hline
\end{tabular}

Figure 6. Boxplot of observed strengths (MPa) of epoxy resin in each of three states, unfilled, filled and with silane coated filler.

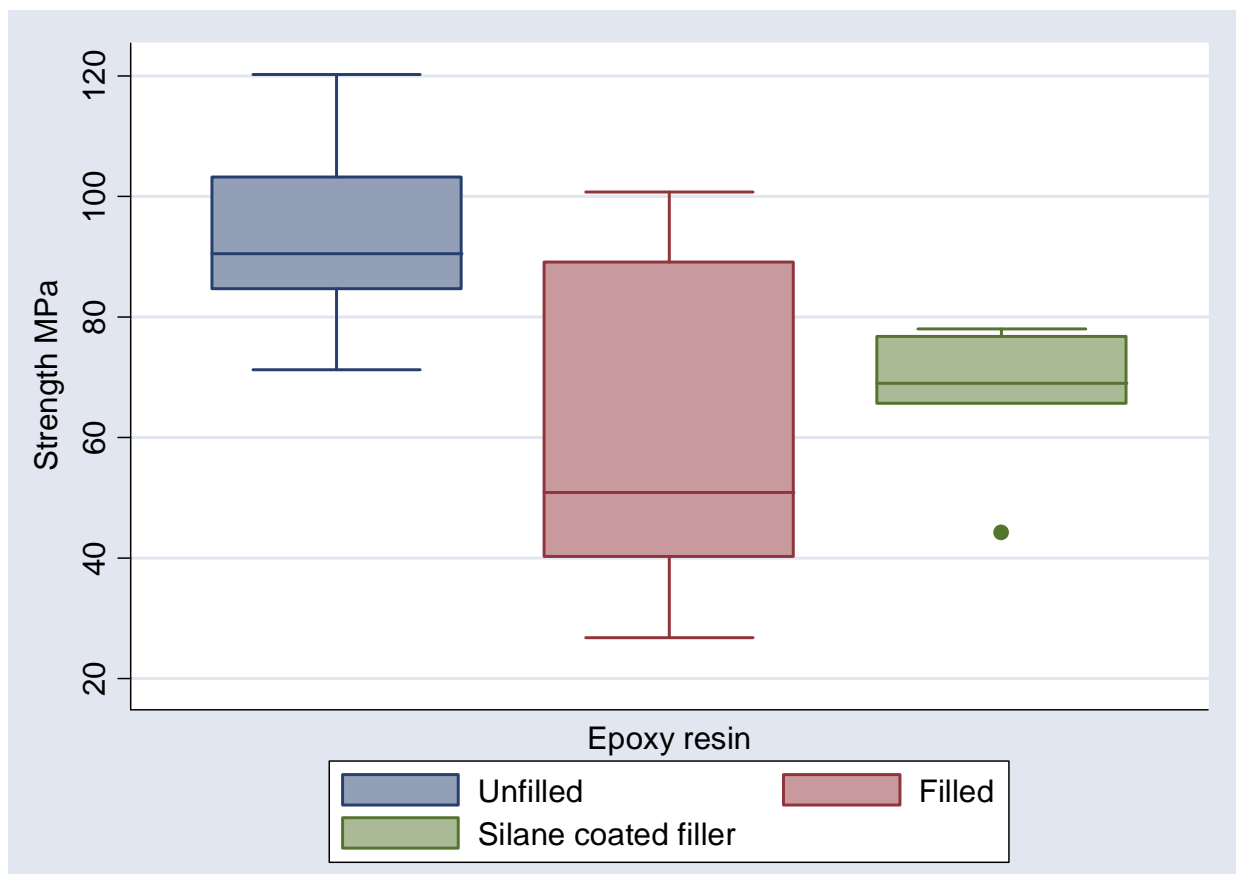


Figure 7. Means and 95\% confidence intervals of the mean for epoxy resin in each of three states, unfilled, filled and with silane coated filler.

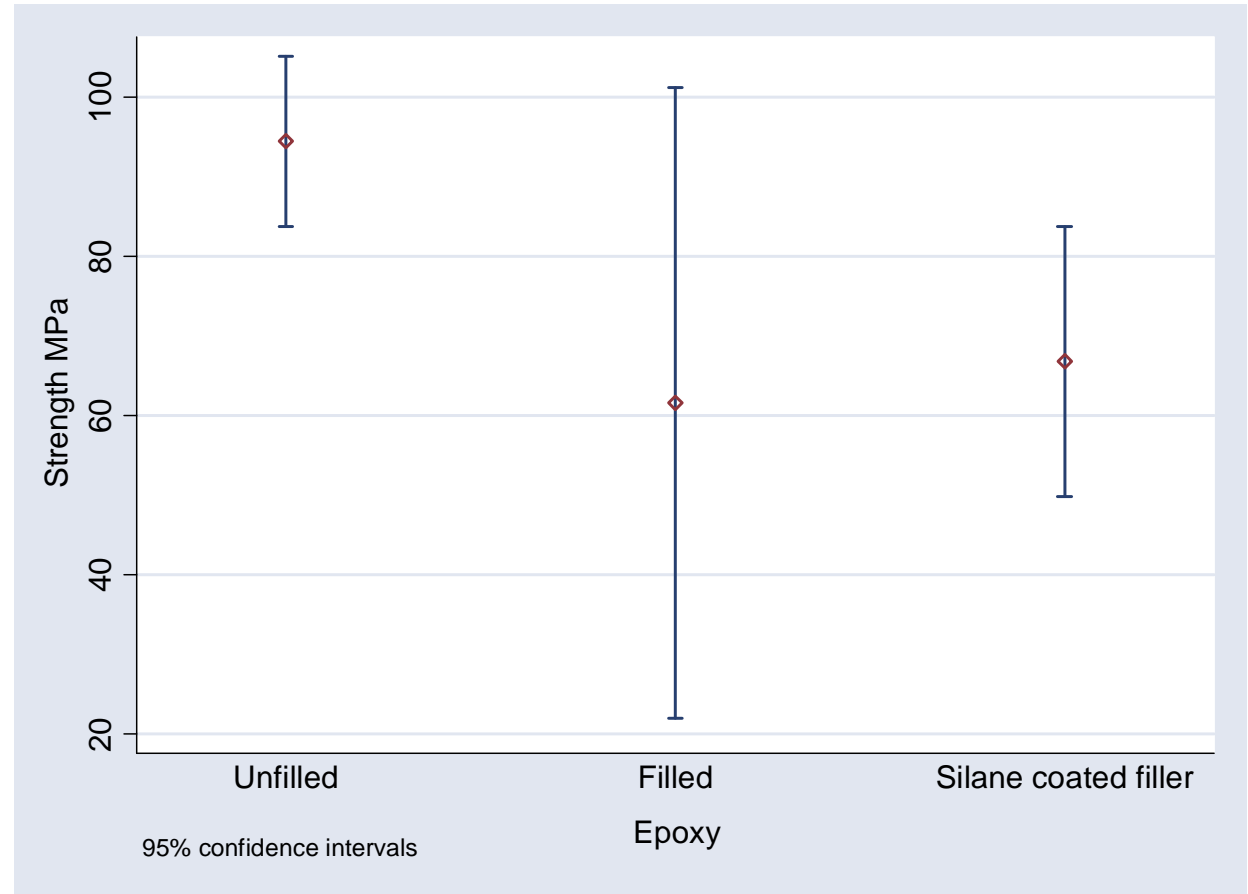

Figure 8. Boxplot of observed strengths (MPa) for Concise, unfilled and with silane coated filler.

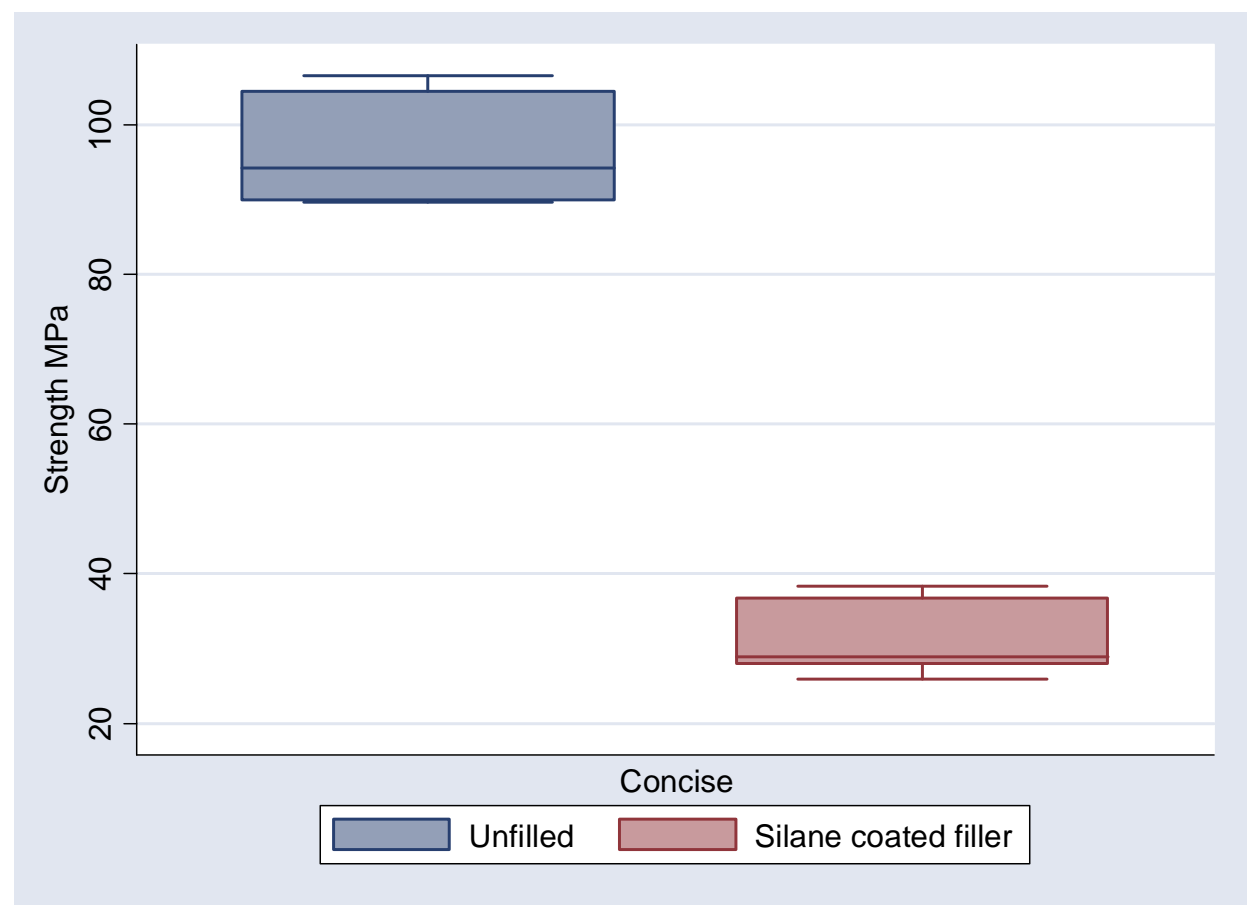


Figure 9. Means and 95\% confidence intervals of the mean for Concise, unfilled and with silane coated filler.

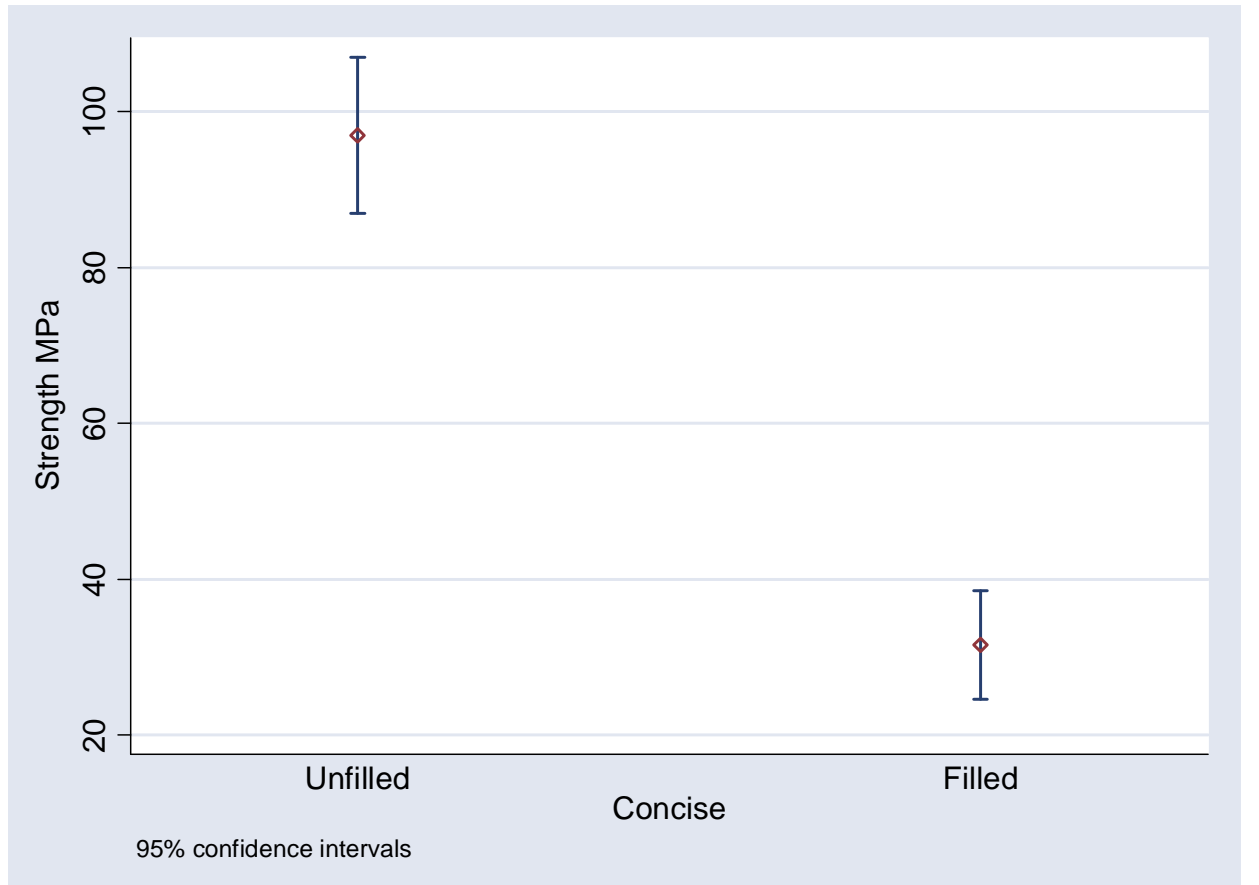

The aim using a silane was to see if it would improve any potential bond between the 3D nanofibres and the resin. A recent investigation in which co-axial polymethyl methacrylate/polyacrylonitrile core nanofibres were infiltrated with Bis-GMA resin prior to being embedded in bulk Bis-GMA, demonstrated a significant increase in flexural strength as a result of the infiltration [20]. Unfortunately the same effect was not observed in our experiment where the flexural strength of the unfilled epoxy control samples was higher than the flexural strength of both silane coated and uncoated nanofibre reinforced epoxy samples.

Although the addition of silane coupling agent to the fibres appeared to reduce the range of observed flexural strengths, it did not significantly improve the mechanical properties of the composite. The reason for this may have been due to improved wetting of the fibres, or direct chemical bonding of the nanofibres to the resin component, or a combination of these two factors. However, the process of silane coating itself may have caused some slumping of the fibres and loss of the 3D structure. In addition the silane coupling agent used in this experiment contained a small amount of acetone as a solvent, which may potentially affect 3D nanofibres.

Similarly with the Concise samples flexural strength was also significantly reduced when compared to the unfilled controls. Indeed the effect was much more pronounced than the differences observed between the filled and unfilled epoxy resin. This suggests that the difficulties in preparation of samples due to the setting characteristics of the Concise compromised the strength to a greater degree than the epoxy resin. The common use of vacuum ovens and light cured Bis-GMA resins in other studies [19,20] appears to minimise the problems associated with incorporation of air into the samples during preparation. This approach would be recommended for any further investigation of this type. 
The fracture surfaces of both the epoxy and Concise samples revealed aggregations of nanofibre fillers that were not in contact with the resin phase of the composite. This, combined with the previously described inclusion of air within the samples, undoubtedly contributed to the reduced flexural strengths observed. Evidence of slumping of the nanofibres towards the bottom of the samples suggested that during resin infiltration the 3D structure had been compromised, either as a result of the manipulation of the nanofibres during placement into the mould, during silane coating, or at the resin infiltration phase (Figure 10).

Figure 10. SEM image of sample 3D nanofibres filled Concise showing clear aggregation of the nanofibre filler at the base of the sample. This suggested that the $3 \mathrm{D}$ integrity of the nanofibre mesh had not been preserved in the process of resin infiltration.

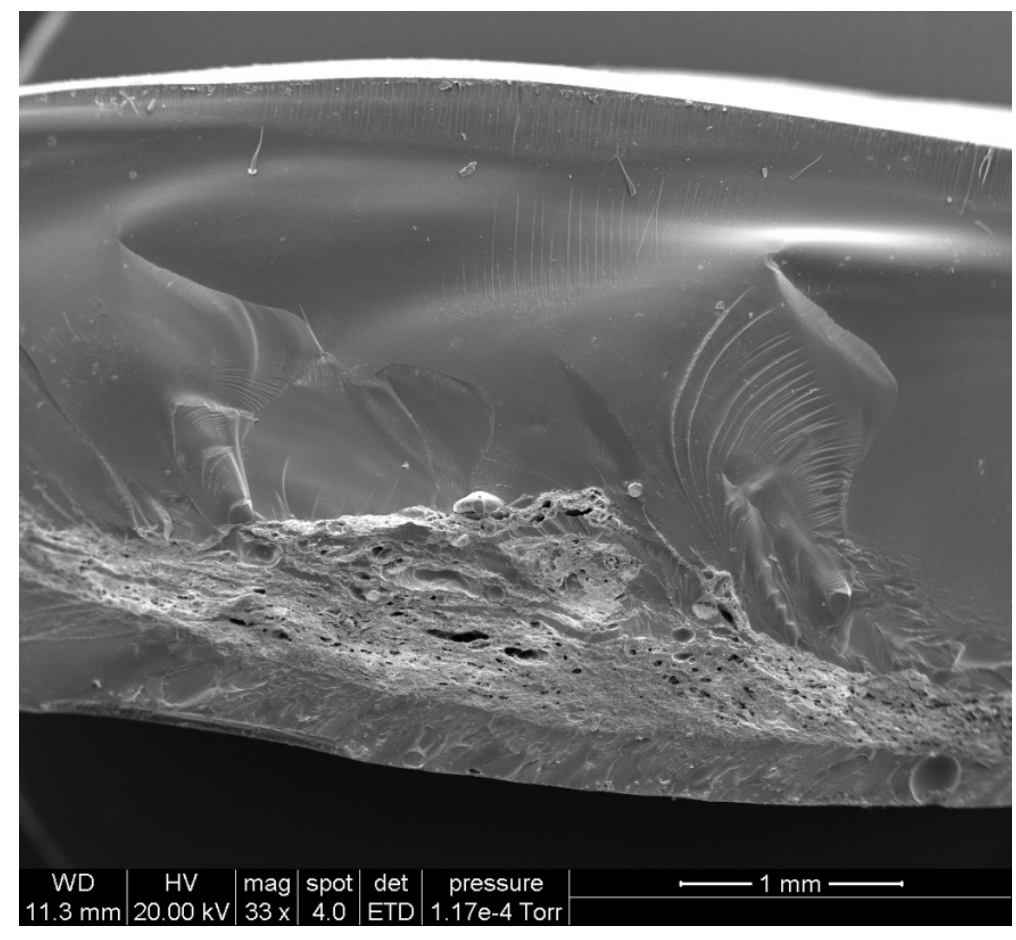

\section{Experimental Section}

Throughout the investigation a standard technique for polymer solution preparation was used. This ensured that any differences in the produced fibres could be attributed to any planned changes in the polymer solution or spinning parameters, rather than due to inconsistencies in solution production. The initial parameters used were based on work by Liu and Hseih (2002) [6] to provide a starting point from which to tailor the fibres to the demands of composite reinforcement. Solvent solutions of acetone and N,N-dimethylacetamide (DMAc) were created in ratios of 2:1 and 3:1 and to each of these was added cellulose acetate powder to produce cellulose acetate concentrations ranging from $14.5 \%$ to 21.5 wt.\%. In each case the cellulose acetate powder was added incrementally to the solvent solution over a 30 min period, whilst being gently stirred using a magnetic stirrer at $100 \mathrm{rpm}$ and at room temperature. Once all the polymer powder had been added, the solution was mixed for a further $2 \mathrm{~h}$ to ensure the polymer was completely dissolved. 


\subsection{Preparation of Electrospun Nanofibres}

The apparatus used for electrospinning is illustrated in Figures 11 and 12. A 25 gauge needle (Precision Glide needles, Becton Dickinson \& Company, NJ, USA) with the bevel removed was used in order to permit the formation of a uniform Taylor cone. The height of the needle and syringe pump (PHD 2000 Infusion, Harvard Apparatus, Edenbridge, UK) were adjusted to negate the effect of gravity on the solution.

Figure 11. Diagram of the electrospinning set-up.
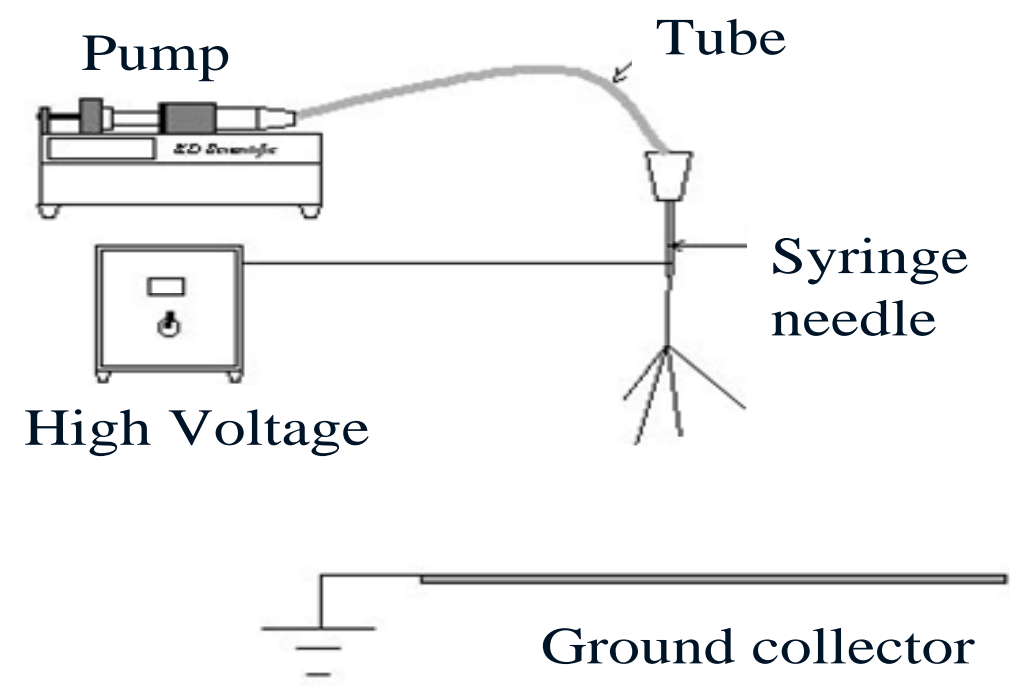

Figure 12. The electrospinning setup showing the syringe, needle and syringe pump.

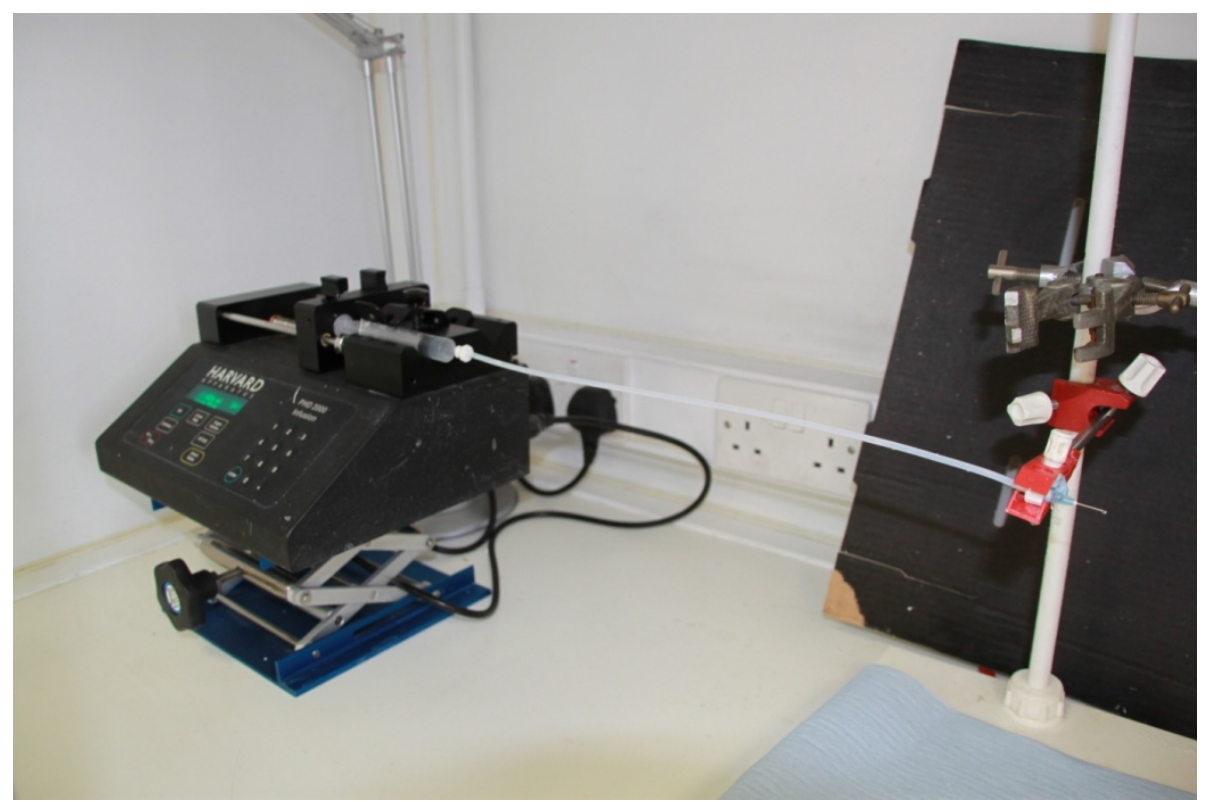

Within this experiment the flow rates under investigation ranged from 0.2 to $25 \mu \mathrm{L} / \mathrm{min}$. In each case the syringe pump was permitted to run for $30 \mathrm{~min}$ prior to electrospinning in order to stabilise the flow rate. The positive terminal of the power supply was connected to the needle, whilst a glass slab 
wrapped in earthed aluminium foil formed the collection plate. The needle tip to collection plate distance was also investigated and ranged from 10 to $30 \mathrm{~cm}$ and the high voltage from 10 to $30 \mathrm{kV}$. Once the apparatus was set up, the solution under test was electrospun for 60 min following which the electrospun cellulose acetate nanofibres were collected and examined under light and scanning electron microscopy.

After each run the spinning and solution parameters (including the polymer concentration and solvent ratios) were altered incrementally in order to assess the effect on the electrospun fibres. The details of all the prepared solutions and spinning parameters are illustrated in Table 1.

Using the aforementioned solution and electrospinning parameters it was possible to produce a flat, virtually 2D mesh of cellulose acetate nanofibres on the collecting plate. The most consistent defect free fibres were produced using $21.5 \%$ cellulose acetate in a solution of 2:1 acetone: DMAc, at a flow rate of $5 \mu \mathrm{L} / \mathrm{min}$, a needle tip to collecting plate distance of $30 \mathrm{~cm}$ and an operating voltage of $10 \mathrm{kV}$.

In order to see if the diameter of the fibres could be reduced and formed into a 3D mesh the solution parameters were retested, but this time following the addition of an ionic salt, lithium chloride, to alter the conductivity of solution for electrospinning (Table 5).

Table 5. Solutions and spinning parameters used to investigate the production of 3D nanofibres.

\begin{tabular}{|c|c|c|c|c|}
\hline $\begin{array}{l}\text { Solution } \\
\text { Number }\end{array}$ & Solution & $\begin{array}{c}\text { Voltage } \\
(\mathrm{kV})\end{array}$ & $\begin{array}{c}\text { Distance to Collecting } \\
\text { Plate (cm) }\end{array}$ & $\begin{array}{c}\text { Flow Rate } \\
(\mu \mathrm{L} / \mathrm{min})\end{array}$ \\
\hline 7 & $\begin{array}{l}\text { 21.5\% cellulose acetate } \\
\text { 1\% lithium chloride } \\
\text { 2:1 acetone: DMAc } \\
\text { 20\% cellulose acetate }\end{array}$ & 10,15 & 30 & $1,2,3,5,10,15$ \\
\hline 8 & $\begin{array}{l}\text { 1\% lithium chloride } \\
\text { 2:1 acetone: DMAc }\end{array}$ & $12.5,15$ & 30 & $0.2,0.5,2$ \\
\hline 9 & $\begin{array}{l}\text { 17.5\% cellulose acetate } \\
\text { 1\% lithium chloride } \\
2: 1 \text { acetone: DMAc }\end{array}$ & 12.5 & 30 & $0.2,1$ \\
\hline 10 & $\begin{array}{l}\text { 20\% cellulose acetate } \\
\text { 1\% lithium chloride } \\
\text { 3:2 acetone: DMAc }\end{array}$ & 15 & 30 & $0.05,0.1$ \\
\hline 11 & $\begin{array}{l}\text { 17.5\% cellulose acetate } \\
\text { 1\% lithium chloride } \\
3: 2 \text { acetone: DMAc }\end{array}$ & 15,20 & 30,15 & $0.1,0.5$ \\
\hline 12 & $\begin{array}{l}\text { 17.5\% cellulose acetate } \\
\text { 1\% lithium chloride } \\
\text { 1:1 acetone: DMAc }\end{array}$ & $\begin{array}{l}10,15 \\
25,30\end{array}$ & 15,30 & $0.05,0.1,1,2,5,10$ \\
\hline 13 & $\begin{array}{l}\text { 15\% cellulose acetate } \\
0.5 \% \text { lithium chloride } \\
\text { 1:1 acetone: DMAc }\end{array}$ & 30 & 30 & 1 \\
\hline 14 & $\begin{array}{l}\text { 17.5\% cellulose acetate } \\
0.5 \% \text { lithium chloride } \\
\text { 1:1 acetone: DMAc }\end{array}$ & 30 & 30 & 1 \\
\hline
\end{tabular}


Table 5. Cont.

\begin{tabular}{|c|c|c|c|c|}
\hline $\begin{array}{l}\text { Solution } \\
\text { Number }\end{array}$ & Solution & $\begin{array}{c}\text { Voltage } \\
(\mathrm{kV})\end{array}$ & $\begin{array}{c}\text { Distance to Collecting } \\
\text { Plate }(\mathrm{cm})\end{array}$ & $\begin{array}{l}\text { Flow Rate } \\
(\mu \mathrm{L} / \mathrm{min})\end{array}$ \\
\hline & $17.5 \%$ cellulose acetate & & & \\
\hline 15 & $\begin{array}{l}0.5 \% \text { lithium chloride } \\
\text { Acetone } \\
17.5 \% \text { cellulose acetate }\end{array}$ & 30 & 30 & 1 \\
\hline 16 & $\begin{array}{l}0.5 \% \text { lithium chloride } \\
3: 1 \text { acetone: DMAc } \\
\text { 17.5\% cellulose acetate }\end{array}$ & 30 & 30 & 1 \\
\hline 17 & $\begin{array}{l}0.5 \% \text { lithium chloride } \\
\text { 3:2 acetone: DMAc } \\
\text { 17.5\% cellulose acetate }\end{array}$ & 30 & 30 & 1 \\
\hline 18 & $\begin{array}{l}0.5 \% \text { lithium chloride } \\
2: 3 \text { acetone: DMAc } \\
17.5 \% \text { cellulose acetate }\end{array}$ & 30 & 30 & 1 \\
\hline 19 & $\begin{array}{l}0.5 \% \text { lithium chloride } \\
1: 3 \text { acetone: DMAc } \\
17.5 \% \text { cellulose acetate }\end{array}$ & 30 & 30 & 1 \\
\hline 20 & $\begin{array}{l}0.5 \% \text { lithium chloride } \\
\text { DMAc }\end{array}$ & 30 & 30 & 1 \\
\hline
\end{tabular}

In each case the resultant fibres were examined using scanning electron microscopy. The combination of parameters producing the best 3D cellulose acetate network was $17.5 \%$ cellulose acetate, $1 \%$ lithium chloride and 1:1 DMAc: acetone solvent solution (Table 5, Solution number 12) with the electrospinning parameters of $30 \mathrm{kV}$, a $15 \mathrm{~cm}$ tip to collecting plate distance and a flow rate of $1 \mu \mathrm{L} / \mathrm{min}$.

\subsection{Production of Filled Composite Specimens for 3 Point Bend Testing}

In order to produce a mould from which composite specimens could be produced for 3 point bend testing, $2 \mathrm{~mm}$ thick Perspex sheet was cut into $25 \mathrm{~mm} \times 10 \mathrm{~mm} \times 2 \mathrm{~mm}$ rectangular blocks. Silicone impression material, mixed according to the manufacturer's recommendations, was then poured over these Perspex blocks and the material allowed to set for $2 \mathrm{~h}$. The Perspex blocks were then freed from their moulds and any unsupported silicone at the edge of the mould removed using a disposable scalpel.

The moulds were then weighed using an analytical balance and 3D cellulose acetate nanofibres gently packed into them using tweezers. The moulds and contained nanofibres were then reweighed in order to determine the weight of the added 3D fibre mesh. In total 15 moulds were filled with 3D fibre mesh in this way.

Using five of the filled moulds, epoxy resin, again weighed using an analytical balance and mixed in accordance with the manufacturer's instructions, was poured into the moulds under vacuum. The resin was allowed to set for $10 \mathrm{~h}$ before being reweighed to determine the filler content. A further five samples were made in the same way, but this time the 3D fibre mesh was precoated with silane using a fine brush followed by air drying for $2 \mathrm{~h}$ and five also and silane coated fibres but in this case the 
polymer was Bis-GMA. Due to the rapid setting of the Bis-GMA there was insufficient time to do this under vacuum and instead a vibrating plate was used to try to minimise air inclusions.

Finally ten unfilled epoxy resin samples and five unfilled Bis-GMA samples were made to act as the controls.

\subsection{Three Point Bend Testing}

Three point bend testing was performed with the samples tested to failure in a custom made testing jig, comprising 2 metal supports $15 \mathrm{~mm}$ apart, in a Lloyd testing machine (LR 5K, Lloyd instruments, UK). The crosshead speed was set at $10 \mathrm{~mm} / \mathrm{min}$. Samples were then examined following testing under SEM.

\section{Conclusions}

The following conclusions were reached as result of this experiment:

1. Defect free nanofibres were successfully electrospun as a flat membrane with fibre diameters in the $483 \mathrm{~nm}$ range using a cellulose acetate polymer and acetone and DMAc solvent solution.

2. The addition of $0.5 \%$ lithium chloride to the polymer solution, and alteration of the spinning parameters produced a 3D self supporting nanofibre mesh. The increased charge density of the electrospun jet resulted in a reduction of the mean fibre diameter from $483 \mathrm{~nm}$ to $286 \mathrm{~nm}$.

3. Infiltration of the 3D nanofibre mesh with both epoxy resin and Concise resin failed to improve the flexural strength of the prototype composite as expected. Although the cause of this was unclear, it was suspected to be as a result of air inclusion and incomplete wetting of the fibres by the resin component.

\section{References}

1. Shah, H.V.; Boyd, S.A.; Sandy, J.R.; Ireland, A.J. Aesthetic labial orthodontic appliances: An update. Orthod. Update 2011, 4, 70-77.

2. Brandt, S. JCO interviews Dr Elliott Silverman, Dr Morton Cohen, and Dr A. J. Gwinnett on bonding. J. Clin. Orthod. 1979, 13, 236-251.

3. Chen, M.H. Update on dental nanocomposites. J. Den. Res. 2010, 89, 549-560.

4. Shah, H.V.; Su, B.; Sandy, J.R.; Ireland, A.J. Electrospinning of 2D and 3D silica nanofibres from a colloidal solution. Ceram. Silikáty 2012, in press.

5. Day, C.J.; Sandy, J.R.; Ireland, A.J. Aerosols and splatter in dentistry-A neglected menace? Den. Update 2006, 33, 601-606.

6. Liu, H.Q.; Hsieh, Y.L. Ultrafine fibrous cellulose membranes from electrospinning of cellulose acetate. J. Polym. Sci. Polym. Phys. 2002, 40, 2119-2129.

7. Wu, X.H.; Wang, L.G.; Huang, Y. Application of electrospun ethyl cellulose fibers in drug release systems. Acta Polym. Sin. 2006, 2, 264-268.

8. Liu, H.Q.; Tang, C. Electrospinning of cellulose acetate in solvent mixture $N, N$-dimethyl acetamide (DMAc)/acetone. Polym. J. 2007, 39, 65-72. 
9. Fong, H. Electrospun Nylon 6 nanofibre reinforced BIS-GMA/TEGDMA dental restorative composite resins. Polymer 2004, 45, 2427-2432.

10. Geng, X.Y.; Kwon, O.H.; Jang, J.H. Electrospinning of chitosan dissolved in concentrated acetic acid solution. Biomaterials 2005, 26, 5427-5432.

11. Demir, M.M.; Yilgor, I.; Yilgor, E.; Erman, B. Electrospinning of polyurethane fibers. Polymer 2002, 43, 3303-3309.

12. Sukigara, S.; Gandhi, M.; Ayutsede, J.; Micklus, M.; Ko, F. Regeneration of Bombyx mori silk by electrospinning-Part 1: Processing parameters and geometric properties. Polymer 2003, 44, 5721-5727.

13. Haas, D.; Heinrich, S.; Greil, P. Solvent control of cellulose acetate nanofibre felt structure produced by electrospinning. J. Mater. Sci. 2010, 45, 1299-1306.

14. Sihn, S.; Kim, R.Y.; Huh, W.; Lee, K.; Roy, A.K. Improvement of damage resistance in laminated composites with electrospun nano-interlayers. Compos. Sci. Technol. 2008, 68, 673-683.

15. Zong, X.H.; Kim, K.; Fang, D.F.; Ran, S.F.; Hsiao, B.S.; Chu, B. Structure and process relationship of electrospun bioabsorbable nanofiber membranes. Polymer 2002, 43, 4403-4412.

16. Schaefer, D.W.; Justice, R.S. How nano are nanocomposites? Macromolecules 2007, 40, 8501-8517.

17. Huang, Z.; Zhang, Y.; Kotaki, M.; Ramakrishna, S. A review on polymer nanofibres by electrospinning and their applications in nanocomposites. Compos. Sci. Technol. 2003, 63, 2223-2253.

18. Zhu, J.; Peng, H.; Rodriguez-Macias, F.; Margrave, J.L.; Khabashesksu, V.N.; Imam, A.M.; Lozano, K.; Barrera, E.V. Reinforcing epoxy polymer composites through covalent integration of functionalized nanotubes. Adv. Funct. Mater. 2004, 14, 643-648.

19. Sun, W.; Cai, Q.; Li, P.; Deng, X.; Wei, Y.; Xu, M.; Yang, X. Post draw PAN-PMMA nanofiber reinforced and toughened Bis-GMA dental restorative composite. Den. Mater. 2010, 26, 873-888.

20. Lin, S.; Cai, Q.; Ji, J.; Sui, G.; Yu, Y.; Yang, X.; Mab, Q.; Wei, Y.; Deng, X. Electrospun nanofiber reinforced and toughened composites through in situ nano-interface formation. Compos. Sci. Technol. 2008, 68, 3322-3329.

(C) 2012 by the authors; licensee MDPI, Basel, Switzerland. This article is an open access article distributed under the terms and conditions of the Creative Commons Attribution license (http://creativecommons.org/licenses/by/3.0/). 